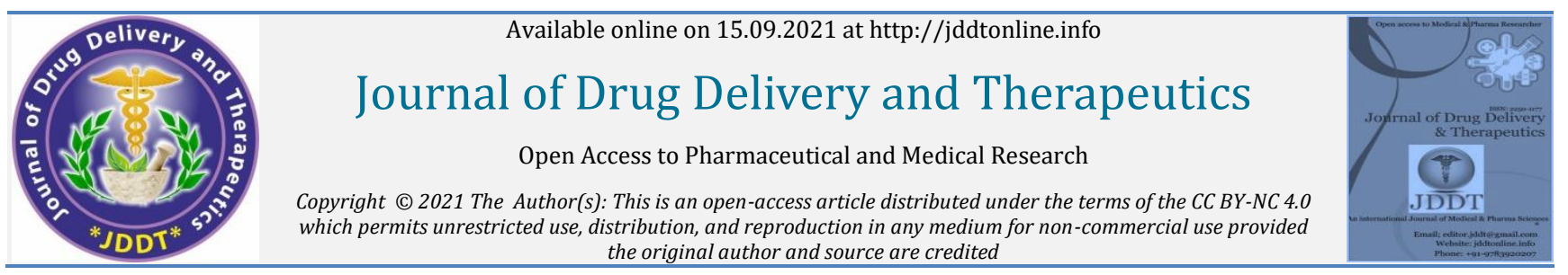

Open Access Full Text Article the original author and source are credited
torition

Research Article

\title{
Evaluation on In Vitro Blood Clot Dissolving Potential of Aqueous Extract of Sida acuta Burm. F. Leaves
}

\author{
Anita Mishra*1, Shadma Siddiqui ${ }^{2}$ and Shreya Tiwari 3,4 \\ ${ }^{1}$ Department of Biotechnology, Vidyadayini Institute of Science, Management and Technology, Bhopal M.P. India \\ ${ }^{2}$ Department of Paramedical Sciences, SAM Global University, Raisen, M.P. India
}

${ }^{3}$ Department of Biotechnology, Shoolini University, Solan, H.P. India

${ }^{4}$ Biomedical \& Biopharmaceutical Division, Lenience Biotech Lab, Bhopal, M.P. India

Article Info:

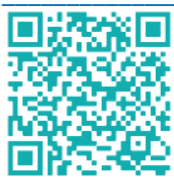

\section{Article History:}

Received 06 July 2021 Reviewed 19 August 2021 Accepted 26 August 2021 Published 15 Sep 2021

\section{Cite this article as:}

Mishra A, Siddiqui S, Tiwari S, Evaluation on In Vitro Blood Clot Dissolving Potential of Aqueous Extract of Sida acuta Burm. F. Leaves, Journal of Drug Delivery and Therapeutics. 2021; 11(5):96-99

DOI: http://dx.doi.org/10.22270/jddt.v11i5.5007

\section{*Address for Correspondence:}

Anita Mishra, Department of Biotechnology, Vidyadayini Institute of Science, Management and Technology, Bhopal M.P. India

\section{Abstract}

Clotting of blood is the vital processes and a perplexing interaction of various mechanisms of circulatory system due of failure of which is sometimes considered as a concern within the circulatory system causing acute myocardial or cerebral infarction which might cause demise. Sida acuta burm. f (Malvaceae) is abundantly growing small perennial shrub utilized by natives for diuretic, anthelmintic, calmative and wound healing properties, and are utilized in treating disorders like blood, bile, liver, nervous, urinary diseases and rheumatism. The present study was intended to evaluate the blood clot dissolving potential of Sida acuta leaf aqueous extract in vitro. The plant material as leaves were locally collected and subjected to phytochemical extraction with distilled water. The preliminary phytochemical tests total phenolic content was estimated by Folin-Ciocalteu's method. In vitro thrombolytic activity of 3 different concentrations of aqueous extract was estimated on goat blood clot compared to the activity of streptokinase. The aqueous extract of $S$. acuta leaves are reported to be rich in alkaloids, flavonoids, tannins, terpenoids and glycosides while the total phenolic content was estimated to be $17.48 \%$ in extract which are mostly responsible for any pharmacological activity. Compared to the thrombolytic activity of standard streptokinase which was $73 \%$, the aqueous leaf extract of $S$. acuta displayed considerable blood clot dissolving activity at concentration $10 \mathrm{mg} / 100 \mu \mathrm{l}, 5.0 \mathrm{mg} / 100 \mu \mathrm{l}$, and $2.5 \mathrm{mg} / 100 \mu \mathrm{l}$ as $41 \%, 34 \%$ and $12 \%$ respectively. This property of plant extract is promising which could be could be exploited in development of new biopharmaceutical and therapeutic agents after stringent further physiological compatibility and in vivo pharmacological studies.

Keywords: Sida acuta, phytochemical extract, thrombolytic activity, streptokinase

\section{INTRODUCTION}

Blood clotting is one of the vital processestakes place in humans, animals and birds ${ }^{1}$. Clotting of blood is a perplexing interaction of various mechanisms, where enactment of the coagulation, fibrinolytic frameworks, disruption of the vascular endothelium, and the generalized triggering of cellular mechanisms prompts to clotting on the surface of monocytes and platelets available in flow ${ }^{2}$. Sometimes blood clots are considered as a concern when formed in the circulatory system due to disturbances in hemostasis resultingin vascular obstruction and causingstern consequences in thrombolytic diseases like acute myocardial or cerebral infarction which might cause demise ${ }^{3}$.Hereditary factors, primary or acquired, play a role in the development of thrombosis ${ }^{2}$. In pharmacological terms the dissolution ofblood clots is regarded as thrombolysisachieved by secondary fibrinolysis by plasmin through application of tissue plasminogen activator equivalents which are plasmin activator proteins. Alteplase, anistreplase, streptokinase, urokinase and tissue plasminogen activator are available in the market as clot dissolving agents ${ }^{4}$. Due to certain negative and life-threatening side effectsanticoagulants currently in use scientists and are interested in finding new alternatives to these anticoagulants of natural and organic origin 5 .

Medicinal plants are the preeminentre source of drugs and pharmacological components as phytomedicine, derived from different parts of the plants ${ }^{6}$.

Sida acuta Burm. f (Malvaceae) is one of those plants as of now utilized by native individualsto manage health issues. This plantis an erect, small perennial herb or small shrub of about $1.5 \mathrm{~m}$ height with branches ${ }^{7}$. It grows abundantly on squander regions, cultivated fields and roadsides.

As a therapeutic all parts of the $S$. acuta are used, however the leaves are the most often demand.Leaves are considered to havediuretic, anthelmintic, calmative and wound healing properties, and are utilized in treating rheumatism ${ }^{8}$, ${ }^{9}$.Stomach torment, hemorrhoids, azoospermia and oligospermia are being used to treat with leaf decoctions of this plant ${ }^{10}$. While, vomiting and gastric disorders were controlled using its leaf juice ${ }^{11}$.Roots are mostly used as a stomachic, diaphoretic and antipyretic in Indian traditional 
medicine. S. acuta also used for disorders like blood, bile, liver,nervous and urinarydiseases, while the hot water extract of whole dried plant is orally used as febrifuge, and abortifacient ${ }^{12}$, 13. Sida acuta is a constituent in Siddha formulation recommended in pulmonary tuberculosis, rheumatism, facial paralysis, sciatica, haemorrhage, spermatorrhoea, leucorrhoea and gonorrhea ${ }^{14}$. Folks say this plant also have thrombolytic activity to some extent. So, the present work was aimed at phytochemical investigation andblood clot dissolving activity of aqueous extract of leaves of Sida acuta under in vitro conditions.

\section{MATERIALS AND METHODS}

\section{Sample Collection and Processing}

The plant material as leaves of Sida acuta (Burm.) were collected from road side in Bhopal City and were authenticated bybotanical literatures and web resources. The collected leave were thoroughly washed in tap water, drained and allowed to dry at room temperature. The dried leaves were then grounded into fine powder followed by defatting with petroleum ether overnight atambient temperature.

\section{Phytochemical Extraction and Analysis}

The defatted leaf powder of $S$. acuta plant was then subjected to phytochemical extraction with pure distilled water by soxhletion method in order to prepare their aqueous extract. The obtained aqueous extract was then concentrated by evaporating the solvent in a boiling water bath. The preliminary phytochemical analysis was done according to the methods described by Harborne ${ }^{15}$, Khandelwal ${ }^{16}$, and Tenguria et al., ${ }^{6}$ which are described as follows;

a. Test for alkaloids: Few drops of Dragendorff's reagent was mixed in diluted stock of extract if yields orange red precipitate demonstrates the presence of alkaloids.

b. Test for tannins: Small amount of diluted extract stockis whenwarmed and followed by addition of 2-3 drops ferric chloride solution gives a dark green colour in solution demonstrates the existence of tannins in extract.

c. Test for terpenoids: About $100 \mu \mathrm{l}$ of stock was diluted with distilled water in a test tubeand carefully $2 \mathrm{ml}$ chloroform $\left(\mathrm{CHCl}_{3}\right)$ was added to it by the side wall of test tube followed by addition of concentrated $\mathrm{H}_{2} \mathrm{SO}_{4}$ $(3 \mathrm{ml})$ in the same way to form a layer. The formation of a reddish brown coloration or a ring at the interface is the indicator for the presence of terpenoids in extract.

d. Test for saponins: The diluted stock of extractwhen warmed a little then had shaken vigorously. The formation of froth or bubbles that stays for 5 minutes at least indicates the presence of saponins.

e. Test for flavonoids: To the diluted stock of extract in a test tube $2-3$ drops of $10 \%$ lead acetate was added. The appearance of a creamy white dirty precipitate demonstrates the presence of flavonoids in extract.

f. Test for glycosides: Benedict reagent was used to check the presence of glycosides in diluted extract. The diluted extract was first warmed they 2-3 drops of Benedicts reagent were added to the reaction tube. The appearance of yellow or orange precipitate indicates the presence of glycoside in extract.

Total Phenolic Content: The total phenolic content (TPC) of the extract was assessed through Folin-Ciocalteu method with suitable modification ${ }^{17}, 18$. The suitably diluted extract was made upto $3 \mathrm{ml}$ with distilled water andwas oxidized $0.5 \mathrm{ml}$ of with Folin-Ciocalteu reagent, and the reaction was neutralized by addition of $2 \mathrm{ml}$ of $20 \%$ sodium carbonate solution. The reaction was permitted to stand for a $60 \mathrm{~min}$ in the dark at room temperature, and absorbance of the resulting blue colour was measured at $650 \mathrm{~nm}$. The TPC was evolved from the calibration curve of gallic acid (using concentrations $0-2 \mathrm{mg} / \mathrm{ml}$ ), and the outcomes were stated as mg of gallic acid equivalent per g dry weight was expressed as mg GA equivalent/L of extract.

\section{In vitro Clot Dissolving Activity}

In vitro experiment was thrombolytic activity was planned for present investigation according to the methods suggested by Sweta et al., (2007), Fatema et al., (2017) and Alawa, et al., (2018) with suitable modification as per present study 19, 4, 5.The goat blood samples were collected from local slaughter house and $0.5 \mathrm{ml}$ of poured into 5 different $1.5 \mathrm{ml}$ microfuge and incubated at $37^{\circ} \mathrm{C}$ for 3 hours to allow the clot formation followed by removal of serum carefully and weight of the clot was measured. Three serial dilutions were made from the $100 \mathrm{mg} / \mathrm{ml}$ stock solution ofaqueous extract of $S$. acuta was. With the help of micropipette, $100 \mu \mathrm{l}$ of aqueous extract from each dilution wasadded in each corresponding separated microfuge touching the surface of blood clot. Streptokinase and sterile distilled water were used in each separate microfuge withblood clot was used as positive and negative control respectively. The set of experiment was incubated at $37{ }^{\circ} \mathrm{C}$ for 2 hours followed by observation in vitro thrombolytic activity. The liquid released after incubation was drained and residual clot was washed with sterile distilled water and moisture was removed by drying. Final weights of microfuge were taken to determine the percentage thrombolytic activity of extract compared to standard through following formulae;

$$
\% \text { Thrombolysis }=\frac{\text { Weight of clot after incubation }}{\text { Weight of clot before incubation }} \times 100
$$

\section{RESULTS AND DISCUSSION}

\section{Preliminary Phytochemical Analysis}

The results of phytochemical analysis of aqueous extract of S. acuta leaves are depicted in table 1 which indicates the aqueous extract is rich in phytoconstituents like alkaloids, flavonoids, tannins, terpenoids and glycosides. Though saponins were reported to be absent in aqueous extracts.

Table 1: Phytochemical Analysis of Sidaacuta (Burm) leaf aqueous extracts

\begin{tabular}{|c|c|c|}
\hline S.N. & Constituents Tested & $\begin{array}{c}\text { Aqueous Extract of } \boldsymbol{S} \\
\text { acuta (Burm) leaves }\end{array}$ \\
\hline 1 & Alkaloids & +4 \\
\hline 2 & Flavonoids & +4 \\
\hline 3 & Tannins & +3 \\
\hline 4 & Saponins & - \\
\hline 5 & Terpenoids & +2 \\
\hline 6 & Glycosides & +4 \\
\hline
\end{tabular}

In an earlier investigation Senthil kumar et al., (2018) also reported more or less similar phytochemical profile for aqueous extract of Sidaacuta leaves ${ }^{20}$. Various phytoconstituents chiefly polyphenols and flavonoids are 
responsible for the biological and pharmacological activity of medicinal plants 18,6 .

\section{Estimation Total Phenolic Content}

In present investigation 20 times diluted $100 \mathrm{mg} / \mathrm{ml}$ stock solution of aqueous extract of $S$. acuta leaves gave an absorbance reading of 0.830 in reaction mixture in digital micro processed spectrophotometer (Electronic India model EI-2305) when subjected to estimation of phenolic content through calibration curve of standard plot with phenol equivalent to gallic acid (table 2 and figure 1) indicates the presence of $17.48 \mathrm{mg} / 100 \mathrm{mg}$ aqueous extract of $S$. acuta leaves or simply the total phenolic content in aqueous extract of $S$. acuta leaves was reported to be $17.48 \%$.Most of the earlier investigation reported TPC in extracts other than aqueous extracts. Muneeswari et al., (2019) reported $31 \pm 0.15 \mathrm{mg} / \mathrm{g}$ TPC in ethanolic extract of $S$. acuta leaves ${ }^{21}$.The presence of tannins and phenolics are responsible of the anti-inflammatory, antimicrobial and free radical scavenging property of any medicinal plant or their extracts $22,23,24$

Table 2: Gallic acid as standard concentration vs absorbance at $650 \mathrm{~nm}$ to plot standard curve for estimation of phenolics in samples Using Folin-Coeucaltue's Method.

\begin{tabular}{|l|l|l|}
\hline S.N. & $\begin{array}{l}\text { GA Concentration in } \\
\mathbf{m g} / \mathbf{m l}\end{array}$ & $\begin{array}{l}\text { Absorbance at } \\
\mathbf{6 5 0} \mathbf{~ n m}\end{array}$ \\
\hline 1 & 2 & 1.891 \\
\hline 2 & 1 & 0.976 \\
\hline 3 & 0.5 & 0.457 \\
\hline 4 & 0.25 & 0.228 \\
\hline 5 & 0.125 & 0.128 \\
\hline
\end{tabular}

\section{Instrument Used}

Single beam visible range digital micro processed spectrophotometer from Electronic India model EI-2305.

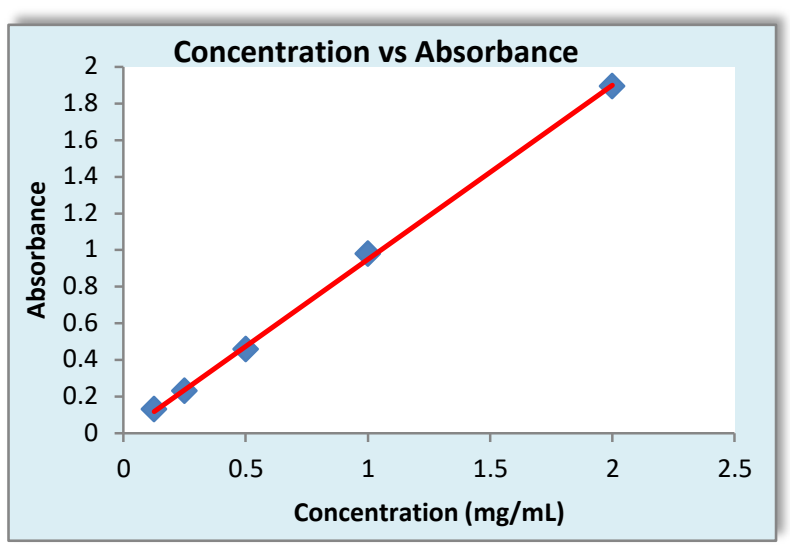

Figure 1: Standard Plot for known concentration of Gallic acid Standardat $650 \mathrm{~nm}$. The Graph is obtained from Excel 2013 linear regression function

\section{In vitro Clot Dissolving Activity}

The in vitro clot dissolving activity of aqueous extract of test plant considered in present study indicates theencouragingoutcomes in prospect of developing of new therapeutic substances. There were 3 different concentrations of extracts used whose percentage blood clot dissolving activity are illustrated in table 3 compared to the standard streptokinase.

Table 3: In vitro clot dissolving activity of aqueous extract of $S$. acuta leavescompared to gel containing Streptokinase

\begin{tabular}{|l|l|l|l|l|}
\hline S. No. & Test Samples & Designation & Concentration & Percentage Clot Dissolving Activity \\
\hline $\mathbf{1}$ & C-1 & -ve Control with water & NA & $1.4 \%$ \\
\hline $\mathbf{2}$ & C-2 & +ve Control with Streptokinase & $0.01 \mathrm{mg}$ & $73 \%$ \\
\hline $\mathbf{3}$ & D-1 & Dilution 1 of extract & $10.0 \mathrm{mg}$ & $41 \%$ \\
\hline $\mathbf{4}$ & D-2 & Dilution 2 of extract & $5.0 \mathrm{mg}$ & $34 \%$ \\
\hline $\mathbf{5}$ & D-3 & Dilution 3 of extract & $2.5 \mathrm{mg}$ & $12 \%$ \\
\hline
\end{tabular}

In present investigation the in vitrothrombolytic activity of aqueous leaf extract of $S$. acuta at a concentration of 10 $\mathrm{mg} / 100 \mu \mathrm{l}$ solution is reported to be $41 \%$ which reduces to $34 \%$ and $12 \%$ when $5.0 \mathrm{mg} / 100 \mu \mathrm{l}$ and $2.55 .0 \mathrm{mg} / 100 \mu \mathrm{l}$ extract solution were used respectively. Streptokinase at a concentration of $0.1 \mathrm{mg} / \mathrm{ml}$ generally produces a thrombolytic activity in range from 80 to $95 \% 25,26$. In present study, Streptokinase displayed an activity of $73 \%$ as positive control at similar concentration that is optimum. The activity of varied concentration of aqueous extract of $S$. acuta leaves and streptokinase, where the dissolution of blood clot due to extracts is considerable (Figure 2).

In terms of blood related studies, Eze, and Nwodo, (2016) reported the significant inhibition of in-vitro haemolysis while investigating the potentiality of membrane stability; platelet aggregation and activities of phospholipase $A_{2}$ and prostaglandin in ethanol extract leaves of Sida acuta ${ }^{27}$. While working on methanolic extract $S$. acuta leaves, Bahar, et al., (2013) reported $24.786 \%$ of thrombolytic activity using 100 $\mu \mathrm{l}$ of $1 \mathrm{mg} / \mathrm{ml}$ and $0.5 \mathrm{mg} / \mathrm{ml}$ concentration ${ }^{28}$. Heavy external blood clots due to any tissue tear or rupture or large accidental wound development is also a problem sometimes when causing painful bandage. Though in present study the thrombolytic activity is reported at higher concentrations, but it is easy and cost effective to obtain the aqueous extracts of any plant material.

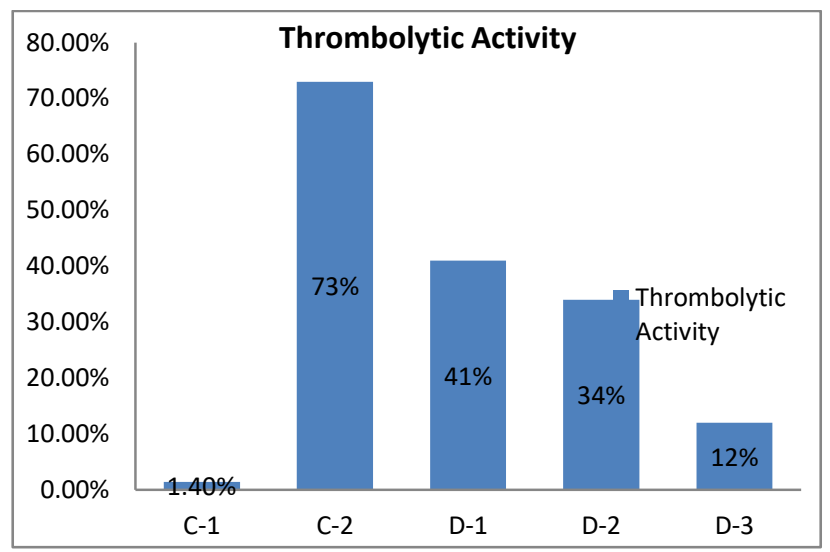

Figure 2: Graphical representation of in vitro blood clot dissolving potential of $S$. acuta aqueous leaf extractand standard streptokinase. 


\section{CONCLUSION}

The outcomes of present investigation indicates that the aqueous extract of $S$. acuta leaves is significantly rich in phenolic contents and variety of phytochemical constituents that could be explored for pharmacological properties in order to develop new drug for the cure of variety of pathological conditions in humans and animals. In present investigation the aqueous extract of $S$. acuta leaves were observed to be promising sources of thrombolytic drug under in vitro experiments. After this preliminary study, further extensive and stringent studies related to their cytotoxic \& genotoxic studies, and physiological compatibility and in vivo pharmacological studies, the thrombolytic property of aqueous extract of $S$. acuta leaves could be exploited in development of new biopharmaceutical and therapeutic agents which could be easily accessible, cost effective and probably safe due to their natural origin.

\section{ACKNOWLEDGEMENT}

The authors are thankful to Mr. Mayank Tenguria (Director \& Scientist) from Lenience Biotech Lab for designing research work, providing necessary funding and laboratory facility to pursue our study.

\section{REFERENCES}

1. Barnes R. The Significance of Thrombosis or Blood Clotting. The British Medical Journal 1879; 1:966-968. https://doi.org/10.1136/bmj.1.965.966

2. Rickles FR, Falanga A. Molecular basis for the relationship between thrombosis and cancer. Thrombosis Research 2001; 102:215-224. https://doi.org/10.1016/S0049-3848(01)002857

3. Sherwani SK, Bashir A, Haider SS, Shah MA, Kazmi SU. Thrombolytic Potential of Aqueous and Methanolic Crude Extracts of Camellia sinensis (Green Tea): In vitro study. Journal of Pharmacognosy and Phytochemistry 2013; 2(1):125-129.

4. Fatema T, Somaia HC, Kamrun NM, KM Imrul Hasif, Tareque Ahmed and Mahbuba Akter. In-vitro thrombolytic activity and phytochemical evaluation of leaf extracts of four medicinal plants of Asteraceae family. Journal of Pharmacognosy and Phytochemistry 2017; 6(4):1166-1169.

5. Alawa P, Tenguria M, Nilosey V. In Vitro Clot Dissolving Activity of Carbomer Based Gel Containing Ethanolic Extract of Calotropis gigantean Leaves. Journal of Drug Delivery and Therapeutics 2018; 8(6-s):101-104. https://doi.org/10.22270/jddt.v8i6s. 2093

6. Tenguria M, Ahirwar KK, Joshi PD. Estimation of Total Polyphenolic Content and Antibiogram Studies of Leaf and Fruit Aqueous Extract of Xanthium Strumarium L. Science Secure Journal of Biotechnology;2(3):83-88.

7. Mohideen S., Sasikala, E., and Gopal, V., (2002). Pharmacognostic Studies on SidaacutaBurm.f. Ancient science of life 2013; 22(1):57-66

8. Anonymous. 'The Wealth of India', Raw Materials, Vol. IX, Publication and Information Directorate, CSIR, New Delhi 1988; 322.

9. Muthalia, M. Siddha MateriaMedica (Medicinal plants Division), Department of Homeopathy, Directorate of Indian Medicines, Chennai 1998; 1998:38.

10. Mshana NR, Abbiw DK, Addae-Mensah I, Adjanouhoun E, Ahyi MRA. Traditional Medicine and Pharmacopoeia Contribution to the Revision of Ethnobotanical and Floristic Studies in Ghana.1st Ed., OAU/STRC, Accra; 2000.
11. Ramachandran VS, Nair NC. Ethnobotanical Observations on Irulars of Tamil Nadu (India). Journal of Economic and Taxonomic Botany 1981; 2:183-190.

12. Kholkute SD, Munshi SR, Naik SD, Jathar VS. Antifertility Activities of Indigenous Plants, Sida carpinifolia and Podocarpus brevifolius in Female Rats. Indian Journal of Experimental Biology 1978; 16:696-698.

13. Khare M, Srivastava SK, and Singh AK. Chemistry and Pharmacology of Genus Sida (Malvaceae) -A Review. J Medicinal and Aromatic Plant Science 2002; 24:430-440.

14. Saraswathy A, Susan T, Gnana RR, Govindarajan S, and Kundu AB. Chemical Investigation of SidaacutaBurm. Bull Med Eth Bot Res. 1998; 19:176-180.

15. Harborne JB. Phytochemical Methods; A Guide to Modern Techniques of Plant Analysis. 3rd edition Chapman and Hall 1983; New York.

16. Khandelwal KR. Practical Pharmacognosy, Technique and Experiments, 23rd Edn: 2005; 149-56.

17. Singleton VL, Orthofer R, Lamuela-Raventos RM. Analysis of Total Phenols and other Oxidation Substrates and Antioxidants by Means of Folin-Ciocalteu Reagent. Methods Enzymol 1999; 299:152-179. https://doi.org/10.1016/S0076-6879(99)990171

18. Tenguria M, Chand P, Upadhyay R Estimation of Total Polyphenolic Content in Aqueous and Methanolic Extracts from the Bark of Acacia nilotica. International Journal of Pharmaceutical Science and Research 2012; 3(9):3458-3461.

19. Sweta P, Rajpal SK, Jayant YD, Hemant JP, Girdhar MT, Hatim FD. Effect of Fagoniaarabica (Dhamasa) on in vitro Thrombolysis. BMC Complementary and Alternative Medicine 2007; 7:36. https://doi.org/10.1186/1472-6882-7-36

20. Senthilkumar RP, Bhuvaneshwari V, Malayaman V, Ranjith kumar R, Sathiyavimal, S. Phytochemical Screening of Aqueous Leaf Extract of SidaacutaBurm. F. and Its Antibacterial Activity. Journal of Emerging Technologies and Innovative Research 2018; 5(8):474-478.

21. Muneeswari P, Bhaskaran SK, Poornima K. Identification of Active Pharmaceuticals of Sida acuta Burm. F Leaves using GCMS and HPTLC Fingerprinting. International Journal of Pharmaceutical Science and Research 2019; 10(3):1194-07.

22. Adel KK, Muhammed SA. Potential of Aqueous and Alcohol Extracts of Quercusin fectoria, Linus musitatissium and Cinnamomum zeylanicium as Antimicrobials and Curing of Antibiotic Resistance in E. coli. Current Research Journal of Biological Sciences 2010; 2(5):333-337.

23. Vaidya V, Mahendrakumar CB, Bhise K. Preliminary Phytochemical Screening of Quercusin fectoria Oliv. for Treatment of Skin Diseases. Journal of Medicinal Plants Research 2013; 7(27):2019-2027. https://doi.org/10.5897/JMPR12.1026

24. Tenguria M, Rathore N, Choudhary A, Tripathi N. Investigation on Effectiveness of Carbopol Based Gel as Anti-Acne Prep. Containing Glycorhiza glabra Root Extracts. Asian Journal of Pharmaceutical Education and Research 2019; 8(2):43-51.

25. Zaman R, Parvez M, Jakaria M, Sayeed MA, Islam M. In vitro Clot Lysis Activity of Different Extracts of Mangifera sylvatica Roxb. Leaves. Research Journal of Medicinal Plant 2015; 9 (3):135140. https://doi.org/10.3923/rjmp.2015.135.140

26. Ashrafudoulla M, Luna NA, Jyothy FH, Khatun T, Rafa TF, Parvin S, Islam MS, Phytochemical and Pharmacological investigation of Calotropis gigantea. Journal of Medicinal Plants Studies 2016; 4(4):245-255.

27. Eze OB, Nwodo OF. In-vitro Stability and Aggregatory Effect of Ethanol Extract Leaves of SidaacutaBurm F. on Human Erythrocyte.Journal of Experimental and Integrative Medicine 2016; 6(3):134-138. https://doi.org/10.5455/jeim.150816.or.156

28. Bahar E, Ara J, Alam M, Nath B, Bhowmik U, Runi N. In-vitro Antioxidant and Thrombolytic activity of Methanol extract of Sida acuta. Journal of Pharmacognosy and Phytochemistry 2013; 2(2):125-133 